\title{
Rapamycin and its analogues (rapalogs) for Tuberous Sclerosis Complex-associated tumors: a systematic review on non-randomized studies using meta-analysis
}

Teguh Haryo Sasongko ${ }^{1,3^{*}}$, Nur Farrah Dila Ismail ${ }^{1,3}$, Nik Mohamad Ariff Nik Abdul Malik ${ }^{1,3}$ and Z. A. M. H. Zabidi-Hussin 2,3

\begin{abstract}
Background: Rapamycin has gained significant attention for its potential activity in reducing the size of TSC-associated tumors, thus providing alternative to surgery. This study aimed at determining the efficacy of rapamycin and rapalogs for reducing the size of TSC-associated solid tumors in patients with Tuberous Sclerosis Complex (TSC).
\end{abstract}

Methods: Our data sources included electronic searches of the PubMed. We included into our meta-analysis any type of non-randomized study that reported the use of rapamycin and rapalogs for reducing the size of TSC-associated solid tumors in patients with TSC. Data was entered into Cochrane Review Manager Version 5.3 and analyzed.

Results: Four case reports and 4 clinical trials were included. Five patients from the case reports (all with SEGA) and 91 patients from the clinical trials (41 with SEGA, 63 with kidney angiomyolipoma and 5 with liver angiomyolipoma) were included into the analysis. Volume and diameter of SEGAs were significantly reduced by mean difference of $1.23 \mathrm{cc}(95 \% \mathrm{Cl}-2.32$ to $-0.13 ; p=0.03)$ and $7.91 \mathrm{~mm}(95 \% \mathrm{Cl}-11.82$ to $-4.01 ; p<0.0001)$, respectively. Volume and mean of sum of longest diameter of kidney angiomyolipomas were significantly reduced by mean difference of $39.5 \mathrm{cc}(95 \% \mathrm{Cl}-48.85$ to $-30.15 ; p<0.00001)$ and $69.03 \mathrm{~mm}(95 \% \mathrm{Cl}-158.05$ to $12.65 ; p=0.008$ ), respectively. In liver angiomyolipomas, however, reduction in tumor size was not evident. Sum of longest diameter of liver angiomyolipomas in 4 patients were enlarged by $2.7 \mathrm{~mm}(95 \% \mathrm{Cl} 28.42$ to -23.02$)$ by the end of treatment, though not significant $(p=0.84)$.

Conclusions: Rapamycin and rapalogs showed efficacy towards reducing the size of SEGA and kidney angiomyolipoma but not liver angiomyolipomas. This finding is strengthening the conclusion of our Cochrane systematic review on the randomized trials.

Keywords: Tuberous sclerosis complex, Rapamycin, Rapalogs, Systematic review, Angiomyolipoma, SubEpendymal giant-cell astrocytoma

\footnotetext{
* Correspondence: teguhharyosasongko@yahoo.com

${ }^{1}$ Human Genome Center, School of Medical Sciences, Universiti Sains Malaysia, USM Health Campus, 16150 Kubang Kerian, Kelantan, Malaysia ${ }^{3}$ Center for Neuroscience Services and Research, Universiti Sains Malaysia, USM Health Campus, 16150 Kubang Kerian, Kelantan, Malaysia

Full list of author information is available at the end of the article
} 


\section{Background}

Tumor development is a hallmark in the pathogenesis and diagnosis of Tuberous Sclerosis Complex (TSC). Nine out of 11 major clinical features in TSC diagnosis constitute the appearance of tumor structures [1]. A significant portion of TSC patients showed tumor development. Cortical tubers (CT) occur in 80-90\% [2, 3], subependymal nodules (SEN) in $90 \%$ [4] and subependymal giant cell astrocytoma (SEGA) in 5-20\% of TSC patients. CT has been associated with seizures and developmental delays [5-7], while SEN is normally dormant but may develop into SEGA which potentially causes ventricular obstruction, visual impairment, focal neurologic deficits and endocrinopathies [4, 8].

Kidney angiomyolipoma occurs in $75 \%$ of TSC patients and is a frequent cause of death due to haemorrhage [9]. Another frequent cause of death among TSC patients is pulmonary lymphangioleiomyomatosis (LAM) which occur in $40 \%$ premenopausal females with TSC [10,9]. Cardiac rhabdomyoma is also commonly found in TSC patients, although generally regress with increasing age [11]. Tumors may also manifest in the skin in the forms of angiofibromas and other cutaneous fibromas [11].

Development of hamartomatous tumors in TSC patients is related to the mTOR (mammalian target of rapamycin) pathway that acts as a central regulator of many functions, including cell size/growth and proliferation. mTOR combines with several other cellular components to form two distinct complexes, termed mTORC1 and mTORC2 [12], of which only mTORC1 is inhibited by rapamycin and rapalogs. Nutrient stimulation stimulates mTORC1 through activation of PI3 kinase (PI3K) and inhibition of Hamartin/Tuberin Complex. Upregulation of mTORC1 activates S6 kinase1 (S6K1) and ribosomal S6 kinase (rS6), and inhibits eukaryotic translation initiation factor 4E-binding protein 1 (4EBP1) and eukaryotic initiation factor 4E (eIF4E), which results in cell growth and proliferation. (Reviewed in [13]). Figure 1 illustrates the mTOR pathway and mTOR inhibition through rapamycinFKBP12 complex.

mTOR kinase inhibition was thought to be a useful approach to systemic therapy for TSC and/or LAM because rapamycin, an mTOR inhibitor, has been shown to normalize dysregulated mTOR signaling in cells that lack normal hamartin or tuberin [14-19].

Rapamycin (otherwise known as sirolimus) is an inhibitor of mTOR. In fact, rapamycin sensitivity has been used as the major criterion to identify mTOR-controlled events [20]. Rapamycin (C51H79NO13) is a macrolide compound that was isolated in 1975 from Streptomyces hygroscopicus found in a soil sample on Easter Island. It prevents activation of $\mathrm{T}$ cells and $\mathrm{B}$ cells by inhibiting their response to interleukin-2 (IL-2). It is an FDAapproved drug for immunosuppression after organ

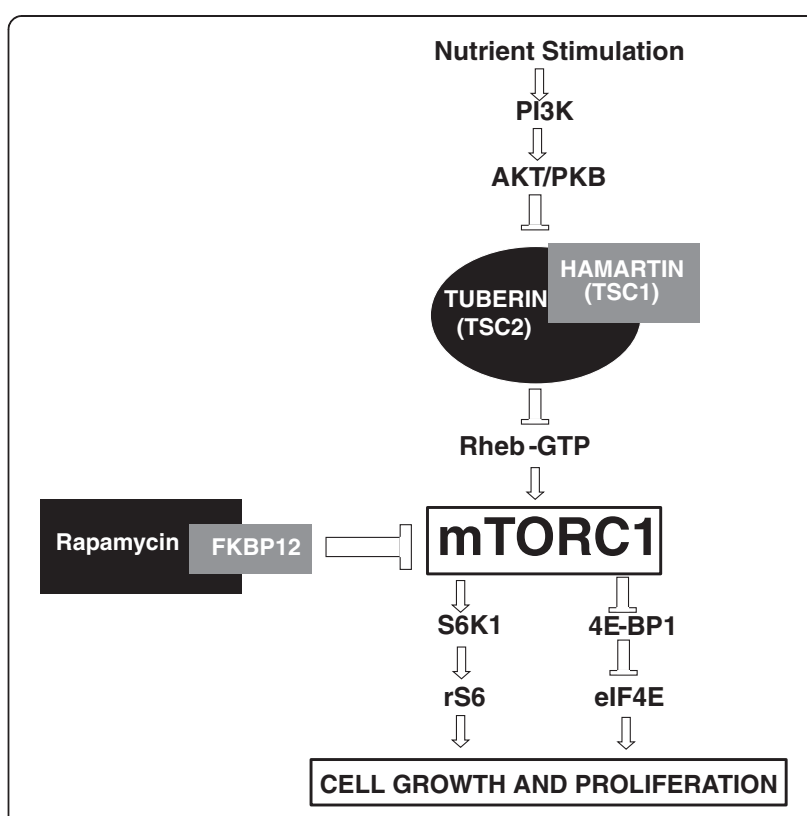

Fig. 1 mTOR pathway and inhibition of mTOR through Rapamycin-FKBP12 complex

transplantation. Rapamycin also possesses both antifungal and antineoplastic properties [21].

The mechanism by which rapamycin inhibits mTOR is not fully understood but rapamycin associates with FKBP12 to bind to the FRB (FKBP12-rapamycin-binding) domain of mTOR. Binding of the rapamycin-FKBP12 complex to mTOR can destabilize the mTORC1 complex and interfere with the activation of mTOR by phosphatidic acid. Several new compounds are available to inhibit mTOR, either by interfering with complex formation (FKBP12-dependent or FKBP12-independent) or by directly inhibiting the catalytic domain of mTOR [22].

A previous study utilizing cohorts of $T s c 2^{+/-}$mice and mouse model of Tsc2-null tumors showed that treatment with an mTOR kinase inhibitor (CCI-779, a rapamycin analogue) reduced the severity of TSC-related disease without significant toxicity [23].

Everolimus, a rapamycin analogue, has been studied in multiple randomized controlled trials for various indications with mostly promising efficacy and safety results such as in de-novo liver transplant patients [24], cardiology patients $[25,26]$, patients with metastatic renal cell carcinoma $[27,28]$, patients with neuroendocrine tumors (NET) $[29,30]$ and breast cancer [31].

A high proportion of tumor manifestations increasingly correspond with the morbidity and mortality due to tumor development in TSC patients. Previous nonhuman studies have shown the potential application of rapamycin and rapalogs for TSC. Our Cochrane Systematic Review on the randomized studies have shown that there is a significant increase in the proportion of 
patients who achieved $50 \%$ reduction in tumor size within the subjects group that received rapamycin and rapalogs (Protocol published [32]). However, we have been unable to measure the rapamycin and rapalogs effect on the absolute tumor size, as this latter outcome was only reported in non-randomized studies. Here we analyzed rapamycin and rapalogs effect on the absolute tumor size in patients with Tuberous Sclerosis Complex.

\section{Methods}

There is no published protocol for this systematic review. This systematic review was checked for completeness based on PRISMA 2009 Checklist [33].

\section{Criteria for considering studies for this review Types of studies}

All types of published non-randomized studies (as defined in the Cochrane Handbook version 5.1 [34]) using English language and encountered online through PubMed searches were analyzed.

\section{Types of participants}

People with known TSC-associated SEGA, kidney angiomyolipoma and/or liver angiomyolipoma as proven by the clinical features designated in the 2012 consensus diagnostic criteria for TSC and/or TSC-causing mutations in either TSC1 or TSC2 gene [1]. Studies and/or participants without solid tumors or non-TSC-associated tumors were excluded.

\section{Types of interventions}

Any rapamycin or its analogues (rapalogs) designed to reduce the size of TSC-associated tumors in patients with Tuberous Sclerosis Complex

\section{Types of outcome measures}

We chose tumor volume or diameter as primary outcome. We also reported adverse effects whenever they are described as related to the rapamycin and rapalogs administration.

\section{Search methods for identification of studies}

Electronic searches in PubMed used keywords "TSC AND [SEGA OR kidney angiomyolipoma OR liver angiomyolipoma] AND [rapamycin OR sirolimus OR tacrolimus OR everolimus]". All published articles and abstracts were searched. The search was limited to reports on human studies using English language.

\section{Data collection and analysis Statistical analysis}

Available data (mean and standard deviation of each cohort study and pooled case reports) was entered into Cochrane Review Manager Version 5.3 [35] for analysis of treatment effects.

\section{Selection of studies}

Studies were selected according to the criteria for considering studies for this review, as described above. Please refer to the PRISMA diagram illustrating the study selection (Fig. 2).

\section{Data extraction}

Data was extracted using the specially designed data acquisition form as used in the Cystic Fibrosis and Genetic Disorders Group of The Cochrane Collaboration. The following items were extracted : type of study, participants and trial characteristics (single/multi-center, countries, eligibility, number of participants in the study, number of participants included in this review), intervention details (type of rapamycin or rapalogs, administering dose, trough level, duration of treatment, median or range of follow-up), outcomes (tumor volume and/or diameter) and rapamycin-related adverse effects.

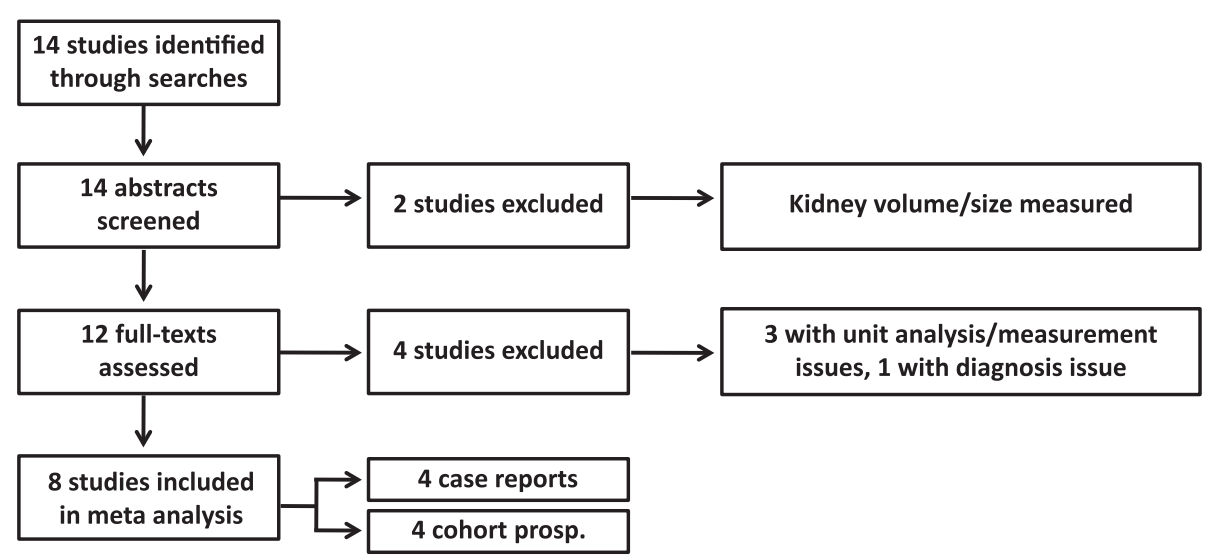

Fig. 2 Study flow diagram (based on The PRISMA Statement [33]) 


\section{Risk of bias assessment}

The risk of bias of each included study was assessed using the 8-item Newcastle-Ottawa Scale for observational studies [36].

\section{Measures of treatment effect}

We recorded continuous data such as tumor volumes or diameter as mean baseline and post treatment values and standard deviation (SD) for each group. We calculated a pooled estimate of the treatment effect at the end of each core length of treatment for each outcome across studies by determining the mean difference. We pooled outcome data from case reports into one group.

\section{Assessment of heterogeneity}

Test for heterogeneity between studies was done using a standard $\mathrm{Chi}^{2}$ test and $\mathrm{I}^{2}$ statistic [37]. The $\mathrm{Chi}^{2}$ test is a statistical test for heterogeneity, whereas $\mathrm{I}^{2}$ assesses the quantity of inconsistency across studies in the metaanalysis. We used a cut-off $P$ value of 0.1 to determine significance. This is because of generally anticipated low power of the reported trials due to the disease being rare. We used the following $\mathrm{I}^{2}$ ranges to interpret heterogeneity: 0 to $40 \%$ : might not be important, 30 to $60 \%$ : may represent moderate heterogeneity, 50 to $90 \%$ : may represent substantial heterogeneity and 75 to $100 \%$ : considerable heterogeneity.

\section{Results and discussion Characteristic of studies Results of the search}

Fourteen studies were identified from the searches (Fig. 2). Screening of abstracts excluded two studies [38, 39] because the studies measured the organ's volume/size instead of the tumor's. These are case reports with one patient each. Further full-text assessments excluded four studies with unit analysis/measurement or diagnosis issues [40-43]. One was a prospective cohort study involving 25 patients with angiomyolipoma or lymphangioleiomyomatosis where the TSC-diagnosed patients were mixed up with non TSC-diagnosed patients [40] and the rest were case reports with 1 patient each [41-43]. This review finally included eight studies consisting of four case reports [44-47] and four prospective cohort studies [48-51].

\section{Included studies (Table 1)}

\section{Characteristics of case reports}

Franz et al. [44] reported four patients with SEGA altogether. However, only three patients ( 1 male 2 females, aged $14.5-21$ years old) were reported with mutations in TSC2 gene. We excluded one patient of this report due to unclear TSC diagnostic data. The patients were treated with rapamycin $2-6 \mathrm{mg} /$ day to achieve trough level of $7.7-10.9 \mathrm{ng} / \mathrm{ml}$ for $2.5-20$ months.

Wienecke et al. [47] reported 1 patient (male, aged 19 years old) with kidney angiomyolipoma, in whom a mutation of TSC2 was identified. The patient was treated with rapamycin $1 \mathrm{mg}$ every other day $-2 \mathrm{mg} /$ day to reach trough level of $4-5 \mathrm{ng} / \mathrm{ml}$ for 7 months. Birca et al. [45] reported 1 patient (female, 8 years old) with SEGA. The patient showed clinical features of TSC as well as continuous deletion of TSC2/PKD1 region. Treatment with rapamycin was $1-2 \mathrm{mg} /$ day to reach trough level of $3.3-$ $4.5 \mathrm{ng} / \mathrm{ml}$. Treatment duration was not mentioned, but last follow-up was after 5 months of treatment. Lam et al. [46] reported 3 patients with TSC-associated SEGA and kidney angiomyolipoma. However, we could only analyzed 1 patient (male, 9 years old) since the remaining 2 patients were reported as percentage decrease in tumor size and

Table 1 Characteristics of included studies

\begin{tabular}{|c|c|c|c|c|c|c|c|c|c|}
\hline \multirow{2}{*}{\multicolumn{2}{|c|}{$\begin{array}{l}\text { Study type } \\
\text { Studies }\end{array}$}} & \multicolumn{4}{|l|}{ Case report } & \multicolumn{4}{|c|}{ Cohort prospective } \\
\hline & & Franz 2006 & Wienecke 2006 & Birca 2010 & Lam 2010 & Krueger 2010 & Dabora 2011 & Lopez 2011 & Davies 2011 \\
\hline \multicolumn{2}{|l|}{$n^{a}$} & 3 & 1 & 1 & 1 & 28 & 36 & 17 & 10 \\
\hline \multirow[t]{2}{*}{ Sex } & $M$ & 1 & 1 & & 1 & 17 & 10 & 8 & NS \\
\hline & $\mathrm{F}$ & 2 & & 1 & & 11 & 26 & 9 & \\
\hline \multicolumn{2}{|c|}{ Age range (years) } & $14.5-21$ & 19 & 8 & 9 & $3-34$ & $19-60$ & $>10$ & NS \\
\hline \multirow[t]{3}{*}{ Genotype } & $\mathrm{TSC} 1$ & & & & & 4 & & & \\
\hline & $\mathrm{TSC} 2$ & 3 & 1 & 1 & 1 & 10 & 14 & & \\
\hline & Unknown & & & & & 14 & 22 & 17 & 10 \\
\hline \multirow[t]{2}{*}{ Rapamycin } & Dose (mg/day) & $2-7$ & 0.5 & 1 & $5-7$ & $3^{b}$ & $2-6$ & 1 & $0.5^{\mathrm{c}}$ \\
\hline & Trough (ng/ml) & $7.7-10.9$ & $4-5$ & $3.3-4.5$ & $10-15$ & $5-15$ & $3-15$ & $4-8^{d}$ & $3-6$ \\
\hline
\end{tabular}

NS Not specified

${ }^{\mathrm{a}} \mathrm{Number}$ of patients included in the analyses

${ }^{b} \mathrm{mg} / \mathrm{m}^{2}$

$\mathrm{c}_{\mathrm{mg} / \mathrm{m}^{2} / \text { day }}$

${ }^{d} \mathrm{ng} / \mathrm{dl}$ 
not the absolute value of tumor volume or diameter. The patient was treated with rapamycin $5-7 \mathrm{mg} /$ day (in combination with carbamazepine that is known to induce rapamycin metabolism) to reach trough level of $10-$ $15 \mathrm{ng} / \mathrm{ml}$ for a year. However, the follow-up reported was only that of 3 months.

\section{Characteristics of prospective cohort studies}

Krueger et al. [51] was described as a prospective, openlabel, phase I-II trial. It was carried out in a single center at the Cincinnati Children's Hospital Medical Center (US). The study reported 28 patients (17 males and 11 females; aged 3 - 34 years old) with definitive diagnosis of TSC and SEGA. The patients were treated with Everolimus orally at a starting daily dose of $3.0 \mathrm{mg}$ per square meter of body-surface area and were subsequently adjusted to attain a whole-blood trough concentration of $5-15 \mathrm{ng} / \mathrm{ml}$. The participants were essentially treated for 6 months with a median length of follow-up of three months.

Dabora et al. [49] was described as an open label, single arm, multicenter study with a Simon two-stage design [52]. It was carried out in six clinical centers at the United States (Boston, Cincinnati, Loma Linda, Hartford, New York and Dallas). The study reported 36 patients (10 males and 26 females; aged 19 - 60 years old) with definitive diagnosis of TSC, all with kidney angiomyolipoma, 13 with SEGA and 4 with liver angiomyolipoma. The patients were treated with Sirolimus orally at a loading dose of $6 \mathrm{mg}$ followed by $2 \mathrm{mg} /$ day to achieve trough level of $3-$ $9 \mathrm{ng} / \mathrm{ml}$ during the first 16 weeks. After 16 weeks, the dose was increased to achieve a trough level of $9-15 \mathrm{ng} /$ $\mathrm{ml}$. The treatment lasted for 12 months with a median length of follow-up of 4 months.

Cabrera-Lopez et al. [48] was described as a phase IV non-blinded, non-controlled clinical trial. It was carried out at a single center in Spain. The study reported 17 patients (8 males and 9 females older than 10 years of age) with TSC diagnosis showing kidney angiomyolipoma. The patients were treated with rapamycin with initial dose of $1 \mathrm{mg} /$ day. The dosage was increased $1 \mathrm{mg} /$ day every for two weeks until it reached stable trough concentration of $4-8 \mathrm{ng} / \mathrm{dl}$. The treatment lasted for 12 months with a median length of follow-up of 6 months.

Davies et al. [50] was described as phase II nonrandomized, open-label multicenter trial. It was carried out in 4 hospitals of the United Kingdom and Switzerland. The study reported 16 patients, out of which only 10 patients were with definitive diagnosis of TSC and showing kidney angiomyolipoma. The patients were treated orally with sirolimus at initial dosage of $0.5 \mathrm{mg} /$ square meter of body surface. The dosage was adjusted to achieve trough concentration of $3-6 \mathrm{ng} / \mathrm{ml}$. The treatment lasted for 24 months with a median length of follow-up of 5 months.

\section{Risk of bias assessment}

The results of the risk of bias assessments for individual studies are reported in Table 2. Overall, each study showed high to low risk of bias.

\section{Effects of interventions on tumor size}

Five patients from the case reports (all with SEGA) and 91 patients from the clinical trials (41 with SEGA, 63 with kidney angiomyolipoma and 5 with liver angiomyolipoma) were included into the analysis. An additional 3 patients from the case reports ( 1 with kidney angiomyolipoma [47] and 2 with SEGA [46]) were described, albeit not systematically analyzed.

\section{SubEpendymal Giant cell Astrocytoma (SEGA) (Table 3)}

In total, there are 5 studies that looked at the effect of rapamycin or rapalogs on SEGA, in which 3 are case reports [44-46] and 2 are prospective cohort [49, 51]. Two studies used tumor volume (cc) [51, 44] and 3 studies used tumor diameter $(\mathrm{mm})[49,45,46]$ as their unit of analysis.

The case reports [44-46] comprised of 5 patients with SEGA. From Franz et al. [44] we included 3 patients using tumor volume (cc) as unit of analysis. Lengths of treatment are variable, ranging from 2.5 - 20 months. Reduction in the tumor volume was noted in all patients, with a mean difference of -1.7 cc (95\% CI -4.6 to $1.2 ; p=0.3$ ). Birca et al. [45] reported one patient on which we took the longest tumor diameter $(\mathrm{mm})$ as unit of analysis. Length of treatment was 5 months. There are two SEGAs found in this patient, from which we took the average for analysis. At 3-month follow-up tumor 1 was reduced from $38.7 \mathrm{~mm}$ to $24.3 \mathrm{~mm}$ while tumor 2 was also reduced from $31.3 \mathrm{~mm}$ to $21.8 \mathrm{~mm}$. No further reduction in tumor size was noted at 5-month follow-up. From Lam et al. [46] we analyzed only one out of 3 patients using tumor longest diameter $(\mathrm{mm})$ as unit of analysis. Length of treatment was 9 months. At 3-month follow-up the tumor was reduced from $35 \mathrm{~mm}-26 \mathrm{~mm}$. No further reduction in tumor size was noted at 6- and 9-month follow-ups. Reduction in the tumor diameter was noted in these 2 patients, with a mean difference of $-12.00 \mathrm{~mm}$ (95\% CI -17.70 to $-6.30 ; p=0.05)$. The other 2 patients showed significant reduction in tumor size of $50-60 \%$ of the pretreatment size [46].

Dabora et al. [49] reported 13 patients with measurable SEGA ranging in diameter from 9-30 mm. However, follow-up data was only available from 11 patients after 12 months of Sirolimus treatment. Tumor regression was observed in 7 cases and SEGA diameter was stable in the other 4 cases. Our analysis showed that the SEGA in these 11 patients were reduced by mean difference of $-4.3 \mathrm{~mm}$ (95\% CI -9.66 to $1.06 ; p=0.1$ ).

Krueger et al. [51] reported 28 patients with SEGA whereby one patient was withdrawn at 4.5 months. This 
Table 2 Risk of bias assessment of included studies

\begin{tabular}{|c|c|c|c|c|c|c|c|c|c|}
\hline Studies & $\begin{array}{l}\text { Representativeness of } \\
\text { exposed cohort }\end{array}$ & $\begin{array}{l}\text { Selection of non- } \\
\text { exposed } \\
\text { cohort }\end{array}$ & $\begin{array}{l}\text { Ascertainment } \\
\text { of exposure }\end{array}$ & Demonstration & Comparability & $\begin{array}{l}\text { Assessment of } \\
\text { outcome }\end{array}$ & $\begin{array}{l}\text { Follow-up } \\
\text { long } \\
\text { enough }^{\mathrm{a}}\end{array}$ & Adequacy of follow-up ${ }^{b}$ & $\begin{array}{l}\text { Total } \\
\text { score }\end{array}$ \\
\hline \multicolumn{10}{|l|}{ Case Reports } \\
\hline Franz 2006 & $\begin{array}{l}\text { Somewhat } \\
\text { representative }\end{array}$ & No non-exposed cohort & Secure record ${ }^{*}$ & Yes $^{*}$ & No & $\begin{array}{l}\text { Record } \\
\text { linkage }^{*}\end{array}$ & Variable & Complete $^{*}$ & 5 \\
\hline $\begin{array}{l}\text { Wienecke } \\
2006\end{array}$ & $\begin{array}{l}\text { Somewhat } \\
\text { representative }\end{array}$ & No non-exposed cohort & Secure record ${ }^{*}$ & Yes $^{*}$ & No & $\begin{array}{l}\text { Record } \\
\text { linkage }^{*}\end{array}$ & Yes $^{*}$ & Complete $^{*}$ & 6 \\
\hline Birca 2010 & $\begin{array}{l}\text { Somewhat } \\
\text { representative }\end{array}$ & No non-exposed cohort & Secure record ${ }^{*}$ & Yes $^{*}$ & No & $\begin{array}{l}\text { Record } \\
\text { linkage }^{*}\end{array}$ & Unclear & Complete $^{*}$ & 5 \\
\hline Lam 2010 & $\begin{array}{l}\text { Somewhat } \\
\text { representative* }\end{array}$ & No non-exposed cohort & Secure record ${ }^{*}$ & Yes $^{*}$ & No & $\begin{array}{l}\text { Record } \\
\text { linkage }\end{array}$ & Yes $^{*}$ & Complete $^{*}$ & 6 \\
\hline \multicolumn{10}{|c|}{ Cohort Prospective } \\
\hline Krueger 2010 & Truly representative ${ }^{*}$ & No non-exposed cohort & Secure record ${ }^{*}$ & Yes $^{*}$ & No & $\begin{array}{l}\text { Record } \\
\text { linkage }\end{array}$ & Yes $^{*}$ & Complete $^{*}$ & 6 \\
\hline Dabora 2011 & Truly representative* & No non-exposed cohort & Secure record ${ }^{*}$ & Yes $^{*}$ & No & $\begin{array}{l}\text { Record } \\
\text { linkage* }\end{array}$ & Yes $^{*}$ & $\begin{array}{l}8 \text { out of } 36 \text { lost follow-up } \\
(22 \%)^{*}\end{array}$ & 6 \\
\hline Davies 2011 & Truly representative* & No non-exposed cohort & Secure record ${ }^{*}$ & Yes $^{*}$ & No & $\begin{array}{l}\text { Record } \\
\text { linkage }\end{array}$ & Yes $^{*}$ & $\begin{array}{l}4 \text { out of } 16 \text { lost follow-up } \\
(25 \%)^{*}\end{array}$ & 6 \\
\hline Lopez 2011 & Truly representative & No non-exposed cohort & Secure record ${ }^{*}$ & Yes $^{*}$ & No & $\begin{array}{l}\text { Record } \\
\text { linkage }\end{array}$ & Yes $^{*}$ & 1 out of 17 lost follow-up $(5 \%)^{*}$ & 6 \\
\hline
\end{tabular}

aLength of follow-up of at least 6 months is considered sufficient

bLost of follow-up $<30 \%$ is considered acceptable; *Indicates point that contribute to Total Score 
Table 3 Outcome on Subependymal Giant Cell Astrocytoma (SEGA)

\begin{tabular}{|c|c|c|c|c|c|c|c|c|c|c|}
\hline \multirow[t]{2}{*}{ Studies } & \multicolumn{5}{|l|}{ Volume (cc) } & \multicolumn{5}{|c|}{ Diameter (mm) } \\
\hline & Baseline & $n$ & After treatment & $n$ & Mean diff (95 \% Cl) & Baseline & $n$ & After treatment & $\mathrm{n}$ & Mean diff (95 \% Cl) \\
\hline Case Reports & $2.9 \pm 2.4$ & 3 & $1.2 \pm 0.9$ & 3 & $-1.7(-4.6,1.2)$ & $35 \pm 3.7$ & 2 & $23 \pm 1.8$ & 2 & $-12.00(-17.70,-6.30)$ \\
\hline Kruger 2010 & $2.45 \pm 2.81$ & 28 & $1.3 \pm 1.48$ & 27 & $-1.01(-2.33,0.03)$ & & & & & \\
\hline Dabora 2011 & & & & & & $16.7 \pm 6.4$ & 13 & $12.4 \pm 6.9$ & 11 & $-4.3(-9.66,1.06)$ \\
\hline \multirow[t]{2}{*}{ Overall Effect } & & & & & $-1.23(-2.32,-0.13)$ & & & & & $-7.91(-11.82,-4.01)$ \\
\hline & & & & & $p=0.03$ & & & & & $p<0.0001$ \\
\hline Heterogeneity & & & & & $C h i^{2}=0.12 ; I^{2}=0 \%$ & & & & & $C h i^{2}=3.72 ; I^{2}=73 \%$ \\
\hline
\end{tabular}

study reported two versions of assessment at 6-month of follow-up; that of the local investigator's and that of the independent central review. We include only the latter in our analysis. Local investigator's assessment examined the tumor volume (cc) at 3, 6, 12, 18 and 24 months. We noted fluctuation in the mean of tumor volume reduction of 3 months $(0.88 \mathrm{cc}), 6$ months $(1.04 \mathrm{cc})$, 12 months $(0.99 \mathrm{cc}), 18$ months $(1.11 \mathrm{cc})$ and 24 months (0.87 cc) as compared to baseline. Our analysis showed that SEGA in 27 patients after 6 months of follow-up were reduced by mean difference of -1.01 (95\% CI -2.33 to $0.03 ; p=0.06)$.

Overall, volume of SEGAs in 30 patients was significantly reduced $(p=0.03)$ after $3-12$ months therapy, by mean difference of -1.23 cc (95\% CI -2.32 to -0.13$)$. Similar pattern was also noted in the diameter of SEGAs in 13 patients $(p<0.0001)$ after $5-12$ months treatment, by mean difference of $-7.91 \mathrm{~mm}$ (95\% CI -11.82 to -4.01$)$.

\section{Kidney angiomyolipoma (Table 4)}

There are 4 studies that looked at the effect of rapamycin on kidney angiomyolipoma. One is a case report [47] and three are cohort prospective [48-50]. Cabrera Lopez et al. [48] and Wienecke et al. [47] used tumor volume (cc), while Dabora et al. [49] and Davies et al. [50] used tumor diameter $(\mathrm{mm})$ as their unit of analysis.

Wienecke et al. [47] reported 1 patient with baseline tumor volume of 134 cc before administration of Rapamycin. Five months following Rapamycin therapy, MRI showed the tumor shrunk to $39 \mathrm{cc}$. The tumor volume was further reduced to $23 \mathrm{cc}$ at 7 months following treatment. At 7 months, Rapamycin treatment was terminated. As a result, 15 months after the initial treatment, the tumor re-grew to $116 \mathrm{cc}$, following which rapamycin was re-instutited. A rapid decrease in tumor volume (to $45 \mathrm{cc}$ ) was noted after 3 months.

Cabrera Lopez et al. [48] reported 17 TSC patients with kidney angiomyolipoma, out of whom one had to be withdrawn from the study after 11 months due to reactivation of an erythema nodosum which was already present at the start of the trial, and another patient was removed from the study after 13 months of treatment due to the appearance of nephrotic proteinuria which disappeared after treatment suspension. Length of treatment was 24 months. Tumor volume was examined at 6-month and 12-month following the treatment. At 6month follow-up the tumor size was significantly decreased by mean difference -34.00 cc (95\% CI 24.62 to $-43.38 ; p=0.0000)$. The tumor size further shrunk at 12-month follow up by mean difference of -39.50 cc (95\% CI -48.85 to $-30.15 ; p=<0.00001$ ).

Dabora et al. [49] reported 36 TSC patients with kidney angiomyolipoma, out of whom 8 were withdrawn from the study. These included 4 who were unable to come for study appointments, and 4 who were taken off study because of a serious adverse event that was judged unrelated to drug therapy ( 1 hospitalized with complicated infectious mononucleosis, 1 diagnosed with a pancreatic neuroendocrine tumor, 1 hospitalized with a kidney angiomyolipoma hemorrhage, 1 hospitalized with

Table 4 Outcome on kidney angiomyolipoma

\begin{tabular}{|c|c|c|c|c|c|c|c|c|c|c|}
\hline \multirow[t]{2}{*}{ Studies } & \multicolumn{5}{|c|}{ Volume (cc) } & \multicolumn{5}{|c|}{ Sum of longest diameter (mm) } \\
\hline & Baseline & $\mathrm{n}$ & After treatment & $n$ & Mean diff $(95 \%$ Cl) & Baseline & $n$ & After treatment & $\mathrm{n}$ & Mean diff (95 \% Cl) \\
\hline Cabrera Lopez 2011 & $62.6 \pm 18.3$ & 17 & $23.1 \pm 7.0$ & 16 & $-39.5(-30.15,-48.85)$ & & & & & \\
\hline Dabora 2011 & & & & & & $212 \pm 146$ & 36 & $145 \pm 113$ & 28 & $-67(-3.55,-130.5)$ \\
\hline Davies 2011 & & & & & & $135.5 \pm 135.6$ & 10 & $62.8 \pm 20.1$ & 7 & $-69.80(15.39,-154.99)$ \\
\hline \multirow[t]{2}{*}{ Overall Effect } & & & & & $-39.5(-48.85,-30.15)$ & & & & & $-69.03(-158.05,12.65)$ \\
\hline & & & & & $p=<0.00001$ & & & & & $p=0.008$ \\
\hline Heterogeneity & & & & & Not applicable & & & & & $C h i^{2}=0.01 ; I^{2}=0 \%$ \\
\hline
\end{tabular}


a neurologic event). Core length of treatment was 12 months. Follow-ups were done at 4, 8 and 12 months. Sum of the longest diameter (SLD) of the tumor $(\mathrm{mm})$ was used as unit of analysis. At 4-month follow up $(\mathrm{n}=33)$, the tumor SLD decreased but not significantly $(p=0.28)$ by mean difference of $-36.00 \mathrm{~mm}$ (95\% CI 28.67 to -100.67 ). At 8-month follow-up $(\mathrm{n}=29)$, the tumor SLD further decreased $(p=0.05)$ by mean difference of $-62.00 \mathrm{~mm}(95 \%$ CI 0.04 to -124.04$)$. At 12 -month follow-up $(n=28)$, the tumor SLD further decreased $(p=0.05)$ by mean difference of $-67.00 \mathrm{~mm}(95 \% \mathrm{CI}-3.55$ to -130.45$)$.

Davies et al. [50] reported 10 TSC patients with kidney angiomyolipoma, out of whom 3 were withdrawn. Length of treatment was 24 months. SLD of the tumors was taken as unit of analysis. Follow-ups were done at 2,6,12 and 24 months. At 2 months $(n=9)$, the tumor SLD was decreased $(p=0.9)$ by mean difference of $-8.00 \mathrm{~mm}$ (95\% CI 118.15 to -134.15$)$. At 6 months $(\mathrm{n}=10)$, the tumor SLD was further decreased $(p=0.79)$ by mean difference of $-16.3 \mathrm{~mm}$ (95\% CI 103.13 to -135.73$)$. At 12 months $(n=8)$, the tumor SLD was decreased $(p=0.11)$ by mean difference of $-69.8 \mathrm{~mm}$ (95\% CI 15.39 to -154.99$)$. Again, at 24 months $(n=7)$, the tumor was decreased further $(p=0.2)$ by mean difference of $-69.8 \mathrm{~mm}$ (95\% CI 15.39 to -154.99$)$. It is of note that at follow-ups of 12 and 24 months, 3 patients with 18 tumor lesions were withdrawn.

Overall, volume of kidney angiomyolipoma in 16 patients was significantly reduced $(p<0.00001)$ by mean difference of -39.5 cc (95\% CI -48.85 to -30.15$)$ after 12 months rapamycin therapy. This reduction was also noted in the mean of SLD of the kidney angiomyolipomas in 35 patients $(p=0.008)$ by $-69.03 \mathrm{~mm}(95 \%$ CI -158.05 to 12.65$)$. In total, 11 patients with kidney angiomyolipomas were withdrawn before 12 months of therapy.

\section{Liver angiomyolipoma}

There is only one study that looked into the effect of rapamycin on liver angiomyolipoma, which is a prospective cohort [49]. This study used the tumor's SLD as the analysis unit. There are 5 TSC patients with measurable liver angiomyolipoma, out of which 1 was withdrawn before 12 months of treatment. Core length of treatment was 12 months. Follow-ups were done at 4, 8 and 12 months. At 4-month follow-up $(n=4)$, the tumor SLD was decreased $(p=0.05)$ by mean difference of $-12.80 \mathrm{~mm}$ (95\% CI -0.1 to -25.5$)$. At 8-month followup $(n=4)$, the tumor SLD was still smaller as compared to that of baseline $(p=0.08)$ by mean difference of $-12.5 \mathrm{~mm}$ (95\% CI 1.33 to -26.33 ) but this slightly re-grew as compared to that at 4-month follow-up. At 12-month follow-up, the tumor SLD was slightly larger $(p=0.84)$ as compared to that of baseline by mean difference of $2.7 \mathrm{~mm}$
(95\% CI 28.42 to -23.02). Reduction of tumor size in liver angiomyolipoma was not evident.

\section{Adverse effects}

Summary of adverse effects found in 99 patients from the included studies was described in Table 5. The most

Table 5 Adverse effects in 99 patients

\begin{tabular}{|c|c|}
\hline Adverse effect & Percentage of patients \\
\hline Oral ulcer & 54.5 \\
\hline Hypertriglyceridemia & 28.3 \\
\hline Upper Respiratory Tract Infection & 26.3 \\
\hline Acne/Acneiform Dermatitis & 19.2 \\
\hline Sinusitis & 16.2 \\
\hline Proteinuria & 16.2 \\
\hline Hypercholesterolemia & 15.2 \\
\hline Tinea/Other Skin problem & 14.1 \\
\hline Leucocytosis & 14.1 \\
\hline Diarrhoea & 12.1 \\
\hline Anemia & 12.1 \\
\hline Otitis Media & 10.1 \\
\hline Pyrexia & 8.1 \\
\hline Cellulitis & 8.1 \\
\hline Joint pain & 8.1 \\
\hline Urinary Tract Infection & 7.1 \\
\hline Headache & 6.1 \\
\hline Lymphopenia & 6.1 \\
\hline Increased Alkaline Phosphatase & 5.1 \\
\hline Irregular menses & 5.1 \\
\hline Nose bleeding & 5.1 \\
\hline Gastroenteritis & 4 \\
\hline Otitis Externa & 4 \\
\hline Incerased ALT, SGPT & 4 \\
\hline Gastric Infection & 3 \\
\hline Cough & 3 \\
\hline Increased Creatinine Kinase & 3 \\
\hline Peripheral Oedema & 3 \\
\hline Fatigue & 3 \\
\hline Vomiting & 2 \\
\hline Gingival Hypertrophy & 1 \\
\hline Myalgia & 1 \\
\hline Acute Pyelonehpritis & 1 \\
\hline Dry skin & 1 \\
\hline Depression & 1 \\
\hline Weight gain & 1 \\
\hline Hypothyroidism & 1 \\
\hline Retinal tear & 1 \\
\hline
\end{tabular}


frequent adverse effects were oral ulcer followed by hypertriglyceridemia and upper respiratory tract infection.

We identified, in this systematic review, 8 studies that fulfill our criteria for study inclusion involving a total of 99 trial participants. Six patients from the case reports (5 with SEGA, 1 with kidney angiomyolipoma) and 91 patients from the prospective cohorts (41 with SEGA, 63 with kidney angiomyolipoma and 5 with liver angiomyolipoma) were included into the analysis. Two other patients were described from a case report, albeit not analyzed.

On the quality of the included studies, we admit that we only included in this analysis non-randomized studies which by itself were a limitation. However, although the case reports may be of moderate to high risk of bias, the prospective cohort studies that we included may be categorized into moderate to low risk of bias, to the extent possible as non-randomized studies. There is a notable variability in the duration of follow-up, which might affect treatment outcome.

Thirty-one patients with SEGA were analyzed for their tumor volume (cc), while 15 patients for their tumor diameter. Analyses using both units showed a significant reduction in the size of SEGAs following the treatment. The volume was significantly reduced after $3-12$ months of rapamycin administration by $1.23 \mathrm{cc}$ and 2.45 stretch of reduction interval. The diameter, on the other hand, showed stretch of reduction interval of 7.81 and a mean reduction of $7.91 \mathrm{~mm}$ after $5-12$ months therapy.

Forty-six patients with kidney angiomyolipomas were analyzed of their tumor's sum of longest diameter (mm), while 17 patients of their tumor volume (cc). Both analyses showed significant reduction in the size of kidney angiomyolipoma following the treatment. The sum of longest diameters was significantly reduced by $69.03 \mathrm{~mm}$ and a stretch of reduction interval of 170.7. The volume was also significantly reduced by $39.50 \mathrm{cc}$ with a stretch of reduction interval of 18.7. However, there are 12 patients withdrawn from the study before completion of 12 months therapy.

These have shown that rapamycin and rapalogs significantly reduce the tumor size in Tuberous Sclerosis patients with SEGA and kidney angiomyolipomas. However, the same reduction in tumor size was not evident in liver angiomyolipomas which involve only a limited set of patients.

Rapamycin has also been tried on other manifestations of Tuberous Sclerosis Complex with mostly promising results, albeit variable degree of evidences. Reports described improvement in facial angiofibroma [53-56], epilepsy [57, 58], cardiac rhabdomyoma [59], lymphangioleiomyomatosis [40,50], fibromatosis and renal cell carcinoma [60] but not the optic nerve tumor [42] among patients with Tuberous Sclerosis Complex.
Our Cochrane systematic review (Protocol published [32]) on the same treatment effect which included only randomized studies [61-63] showed that there is a significant increase in the proportion of patients who achieved $50 \%$ reduction in tumor size within the participants group that received rapamycin and rapalogs. This used dichotomous data for its analyses. The current article meta-analyzed non-randomized studies for the effect of rapamycin and rapalogs on tumor size and used continuous data for its analyses (actual tumor volume and diameter).

Adverse effects of the rapamycin treatment should be highlighted given that slightly more than half of the patients showed at least one of the listed adverse effects (Table 5). However, only very few were reported to develop serious conditions $[49,51]$.

\section{Conclusion}

As a conclusion, we have shown that rapamycin and rapalogs reduce the size of SEGA and kidney angiomyolipoma in patients with Tuberous Sclerosis Complex. This result strengthens our Cochrane systematic review on randomized studies. However, it is of note that we are unable to rule out the possibility of publication bias where authors only report positive outcomes and there may be many instances where no response was unreported.

\section{Competing interests}

The authors declare that they have no competing interests.

\section{Authors' contributions}

THS and ZAMH-ZH developed the concept for the manuscript. NFDI and NMANAM performed the search and extracted the data. THS and ZAMH-ZH analyzed the data. THS drafted the manuscript. ZAMH-ZH, NFDI and NMANAM critically participated in discussions to develop the manuscript. All authors read and approved the final manuscript.

\section{Acknowledgements}

Studies on Tuberous Sclerosis Complex in Universiti Sains Malaysia are funded by the USM Research University Grant Nbr. 1001/PPSP/812137 for Dr. Teguh Haryo Sasongko and USM Neuroscience Excellence Grant Nbr. 304.PPSP.652205.K134 for Professor Zabidi Azhar Mohd. Hussin.

\section{Author details}

${ }^{1}$ Human Genome Center, School of Medical Sciences, Universiti Sains Malaysia, USM Health Campus, 16150 Kubang Kerian, Kelantan, Malaysia. ${ }^{2}$ Department of Pediatrics, School of Medical Sciences, Universiti Sains

Malaysia, USM Health Campus, 16150 Kubang Kerian, Kelantan, Malaysia. ${ }^{3}$ Center for Neuroscience Services and Research, Universiti Sains Malaysia, USM Health Campus, 16150 Kubang Kerian, Kelantan, Malaysia.

Received: 5 June 2015 Accepted: 3 August 2015

Published online: 12 August 2015

References

1. Northrup H, Krueger DA, International Tuberous Sclerosis Complex Consensus $\mathrm{G}$. Tuberous sclerosis complex diagnostic criteria update: recommendations of the 2012 International tuberous sclerosis complex consensus conference. Pediatr Neurol. 2013;49(4):243-54. doi:10.1016/ j.pediatrneurol.2013.08.001.

2. Crino $P B$, Nathanson $K L$, Henske EP. The tuberous sclerosis complex. N Engl J Med. 2006;355(13):1345-56. doi:10.1056/NEJMra055323. 
3. Baskin Jr HJ. The pathogenesis and imaging of the tuberous sclerosis complex. Pediatr Radiol. 2008;38(9):936-52. doi:10.1007/s00247-008-0832-y.

4. Kopp CM, Muzykewicz DA, Staley BA, Thiele EA, Pulsifer MB. Behavior problems in children with tuberous sclerosis complex and parental stress. Epilepsy Behav. 2008;13(3):505-10. doi:10.1016/j.yebeh.2008.05.010.

5. Kwiatkowski DJ, Manning BD. Tuberous sclerosis: a GAP at the crossroads of multiple signaling pathways. Hum Mol Genet. 2005;14 Spec No. 2:R251-8. doi:10.1093/hmg/ddi260.

6. Wong M. Mechanisms of epileptogenesis in tuberous sclerosis complex and related malformations of cortical development with abnormal glioneuronal proliferation. Epilepsia. 2008;49(1):8-21. doi:10.1111/j.1528-1167.2007.01270.x.

7. Major P, Rakowski S, Simon MV, Cheng ML, Eskandar E, Baron J, et al. Are cortical tubers epileptogenic? Evidence from electrocorticography. Epilepsia. 2009;50(1):147-54. doi:10.1111/j.1528-1167.2008.01814.x.

8. Goh S, Butler W, Thiele EA. Subependymal giant cell tumors in tuberous sclerosis complex. Neurology. 2004;63(8):1457-61.

9. Franz DN. Non-neurologic manifestations of tuberous sclerosis complex. J Child Neurol. 2004;19(9):690-8.

10. Johnson SR. Lymphangioleiomyomatosis. Eur Respir J. 2006;27(5):1056-65. doi:10.1183/09031936.06.00113303.

11. Yates JR. Tuberous sclerosis. Eur J Hum Genet. 2006;14(10):1065-73. doi:10.1038/sj.ejhg.5201625.

12. Bhaskar PT, Hay N. The two TORCs and Akt. Dev Cell. 2007;12(4):487-502 doi:10.1016/j.devcel.2007.03.020.

13. Franz DN, Weiss BD. Molecular therapies for tuberous sclerosis and neurofibromatosis. Curr Neurol Neurosci Rep. 2012;12(3):294-301. doi:10.1007/s11910-012-0269-4.

14. Gao X, Pan D. TSC1 and TSC2 tumor suppressors antagonize insulin signaling in cell growth. Genes Dev. 2001;15(11):1383-92. doi:10.1101/gad.901101.

15. Goncharova EA, Goncharov DA, Eszterhas A, Hunter DS, Glassberg MK, Yeung RS, et al. Tuberin regulates p70 S6 kinase activation and ribosomal protein 56 phosphorylation. A role for the TSC2 tumor suppressor gene in pulmonary lymphangioleiomyomatosis (LAM). J Biol Chem. 2002;277(34):30958-67. doi:10.1074/jbc.M202678200.

16. Inoki K, Li Y, Zhu T, Wu J, Guan KL. TSC2 is phosphorylated and inhibited by Akt and suppresses mTOR signalling. Nat Cell Biol. 2002;4(9):648-57. doi:10.1038/ncb839.

17. Kwiatkowski DJ, Zhang H, Bandura JL, Heiberger KM, Glogauer M, el-Hashemite $\mathrm{N}$, et al. A mouse model of TSC1 reveals sex-dependent lethality from liver hemangiomas, and up-regulation of p70s6 kinase activity in Tsc1 null cells. Hum Mol Genet. 2002;11(5):525-34

18. Manning BD, Tee AR, Logsdon MN, Blenis J, Cantley LC. Identification of the tuberous sclerosis complex-2 tumor suppressor gene product tuberin as a target of the phosphoinositide 3-kinase/akt pathway. Mol Cell. 2002;10(1):151-62.

19. Potter CJ, Pedraza LG, Xu T. Akt regulates growth by directly phosphorylating Tsc2. Nat Cell Biol. 2002;4(9):658-65. doi:10.1038/ncb840.

20. Ballou LM, Lin RZ. Rapamycin and mTOR kinase inhibitors. J Chem Biol. 2008;1(1-4):27-36. doi:10.1007/s12154-008-0003-5.

21. Rapamune. RxList: The internet drug index. 2013.

22. Ehninger D, Silva AJ. Rapamycin for treating Tuberous sclerosis and Autism spectrum disorders. Trends Mol Med. 2011;17(2):78-87. doi:10.1016/ j.molmed.2010.10.002.

23. Lee L, Sudentas P, Donohue B, Asrican K, Worku A, Walker V, et al. Efficacy of a rapamycin analog (CCl-779) and IFN-gamma in tuberous sclerosis mouse models. Gene Chromosome Cancer. 2005;42(3):213-27. doi:10.1002/gcc.20118.

24. Fischer L, Saliba F, Kaiser GM, De Carlis L, Metselaar HJ, De Simone P, et al. Three-year outcomes in de novo liver transplant patients receiving everolimus with reduced tacrolimus: follow-up results from a randomized, multicenter study. Transplantation. 2015;99(7):1455-62. doi:10.1097/ TP.0000000000000555.

25. Ribichini F, Romano M, Rosiello R, La Vecchia L, Cabianca E, Caramanno G, et al. A clinical and angiographic study of the XIENCE V everolimus-eluting coronary stent system in the treatment of patients with multivessel coronary artery disease: the EXECUTIVE trial (EXecutive RCT: evaluating XIENCE V in a multi vessel disease). JACC Cardiovasc Interv. 2013;6(10):1012-22. doi:10.1016/ j.jcin.2013.05.016.

26. Alfonso F, Perez-Vizcayno MJ, Cardenas A, Garcia Del Blanco B, Garcia-Touchard A, Lopez-Minguez JR, et al. A prospective randomized trial of drug-eluting balloons versus Everolimus-Eluting stents in patients with in-stent restenosis of drug-eluting stents: the ribs IV randomized clinical trial. J Am Coll Cardiol. 2015;66(1):23-33. doi:10.1016/j.jacc.2015.04.063.
27. Motzer RJ, Escudier B, Oudard S, Hutson TE, Porta C, Bracarda S, et al. Phase 3 trial of everolimus for metastatic renal cell carcinoma: final results and analysis of prognostic factors. Cancer. 2010;116(18):4256-65. doi:10.1002/ cncr.25219.

28. Ravaud A, Barrios CH, Alekseev B, Tay MH, Agarwala SS, Yalcin S, et al. RECORD-2: phase II randomized study of everolimus and bevacizumab versus interferon alpha-2a and bevacizumab as first-line therapy in patients with metastatic renal cell carcinoma. Ann Oncol. 2015:26(7):1378-84. doi:10.1093/annonc/mdv170.

29. Castellano D, Bajetta E, Panneerselvam A, Saletan S, Kocha W, O'Dorisio T, et al. Everolimus plus octreotide long-acting repeatable in patients with colorectal neuroendocrine tumors: a subgroup analysis of the phase III RADIANT-2 study. Oncologist. 2013;18(1):46-53. doi:10.1634/ theoncologist.2012-0263.

30. Pavel ME, Hainsworth JD, Baudin E, Peeters M, Horsch D, Winkler RE, et al. Everolimus plus octreotide long-acting repeatable for the treatment of advanced neuroendocrine tumours associated with carcinoid syndrome (RADIANT-2): a randomised, placebo-controlled, phase 3 study. Lancet. 2011;378(9808):2005-12. doi:10.1016/S0140-6736(11)61742-X

31. Qiao L, Liang Y, Mira RR, Lu Y, Gu J, Zheng Q. Mammalian target of rapamycin (mTOR) inhibitors and combined chemotherapy in breast cancer: a meta-analysis of randomized controlled trials. Int J Clin Exp Med. 2014;7(10):3333-43.

32. Sasongko TH IN, Nik Abdul Malik NMA, Zabidi-Hussin ZAMH. Rapamycin and its analogues (rapalogs) for tuberous sclerosis complex (Protocol). Cochrane Database Syst Rev 2014 (9). doi:10.1002/14651858.CD011272.pub2.

33. Moher D, Liberati A, Tetzlaff J, Altman DG. Preferred reporting items for systematic reviews and meta-analyses: the PRISMA statement. PLoS Med. 2009;6(7):e1000097. doi:10.1371/journal.pmed.1000097.

34. Higgins JPT GSe. Cochrane Handbook for Systematic Reviews of Interventions Version 5.1.0 [updated March 2011]. The Cochrane Collaboration; 2011.

35. Review Manager (RevMan) [Computer Program]. Version 5.3. Copenhagen: The Nordic Cochrane Centre, The Cochrane Collaboration, 2014

36. Wells GA Shea B, O'Connell D, Peterson J, Welch V, Losos M, Tugwell P. The Newcastle-Ottawa Scale (NOS) for assessing the quality if nonrandomized studies in meta-analyses. Ottawa Hospital Research Institute. http:// www.ohri.ca/programs/clinical_epidemiology/oxford.asp. Accessed 1 May 2015

37. Higgins JP, Thompson SG, Deeks JJ, Altman DG. Measuring inconsistency in meta-analyses. BMJ. 2003;327(7414):557-60. doi:10.1136/bmj.327.7414.557

38. Herry I, Neukirch C, Debray MP, Mignon F, Crestani B. Dramatic effect of sirolimus on renal angiomyolipomas in a patient with tuberous sclerosis complex. Eur J Intern Med. 2007;18(1):76-7. doi:10.1016/j.ejim.2006.07.017.

39. Peces R, Peces C, Cuesta-Lopez E, Perez-Duenas V, Vega-Cabrera C, Azorin S, et al. Low-dose rapamycin reduces kidney volume angiomyolipomas and prevents the loss of renal function in a patient with tuberous sclerosis complex. Nephrol Dial Transplant. 2010;25(11):3787-91. doi:10.1093/ndt/gfq456.

40. Bissler JJ, McCormack FX, Young LR, Elwing JM, Chuck G, Leonard JM, et al. Sirolimus for angiomyolipoma in tuberous sclerosis complex or lymphangioleiomyomatosis. N Engl J Med. 2008;358(2):140-51. doi:10.1056/ NEJMoa063564.

41. Koenig MK, Butler IJ, Northrup H. Regression of subependymal giant cell astrocytoma with rapamycin in tuberous sclerosis complex. J Child Neurol. 2008;23(10):1238-9. doi:10.1177/0883073808321764.

42. Sparagana SP, Wilkes DC, Thompson CE, Bowers DC. Optic nerve tumor in tuberous sclerosis complex is not responsive to sirolimus. Pediatr Neurol. 2010;42(6):443-6. doi:10.1016/j.pediatrneurol.2010.01.016.

43. Yalon M, Ben-Sira L, Constantini S, Toren A. Regression of subependymal giant cell astrocytomas with RAD001 (Everolimus) in tuberous sclerosis complex. Childs Nerv Syst. 2011;27(1):179-81. doi:10.1007/s00381-010-1222-y.

44. Franz DN, Leonard J, Tudor C, Chuck G, Care M, Sethuraman G, et al. Rapamycin causes regression of astrocytomas in tuberous sclerosis complex. Ann Neurol. 2006;59(3):490-8. doi:10.1002/ana.20784.

45. Birca A, Mercier C, Major P. Rapamycin as an alternative to surgical treatment of subependymal giant cell astrocytomas in a patient with tuberous sclerosis complex. J Neurosurg Pediatr. 2010;6(4):381-4. doi:10.3171/2010.7.PEDS10221.

46. Lam C, Bouffet E, Tabori U, Mabbott D, Taylor M, Bartels U. Rapamycin (sirolimus) in tuberous sclerosis associated pediatric central nervous system tumors. Pediatr Blood Cancer. 2010;54(3):476-9. doi:10.1002/ pbc.22298. 
47. Wienecke R, Fackler I, Linsenmaier U, Mayer K, Licht T, Kretzler M. Antitumoral activity of rapamycin in renal angiomyolipoma associated with tuberous sclerosis complex. Am J Kidney Dis. 2006;48(3):e27-9. doi:10.1053/ j.ajkd.2006.05.018.

48. Cabrera Lopez C, Marti T, Catala V, Torres F, Mateu S, Ballarin Castan J, et al. Effects of rapamycin on angiomyolipomas in patients with tuberous sclerosis. Nefrologia. 2011;31(3):292-8. doi:10.3265/Nefrologia.pre2011. Apr.10812.

49. Dabora SL, Franz DN, Ashwal S, Sagalowsky A, DiMario Jr FJ, Miles D, et al. Multicenter phase 2 trial of sirolimus for tuberous sclerosis: kidney angiomyolipomas and other tumors regress and VEGF- D levels decrease. PLoS One. 2011;6(9):e23379. doi:10.1371/journal.pone.0023379.

50. Davies DM, de Vries PJ, Johnson SR, McCartney DL, Cox JA, Serra AL, et al. Sirolimus therapy for angiomyolipoma in tuberous sclerosis and sporadic lymphangioleiomyomatosis: a phase 2 trial. Clin Cancer Res. 2011;17(12):4071-81. doi:10.1158/1078-0432.CCR-11-0445.

51. Krueger DA, Care MM, Holland K, Agricola K, Tudor C, Mangeshkar P, et al. Everolimus for subependymal giant-cell astrocytomas in tuberous sclerosis. N Engl J Med. 2010;363(19):1801-11. doi:10.1056/NEJMoa1001671.

52. Simon R. Optimal two-stage designs for phase II clinical trials. Control Clin Trials. 1989;10(1):1-10.

53. Truchuelo T, Diaz-Ley B, Rios L, Alcantara J, Jaen P. Facial angiofibromas treated with topical rapamycin: an excellent choice with fast response. Dermatol Online J. 2012;18(1):15.

54. Wataya-Kaneda M, Tanaka M, Nakamura A, Matsumoto S, Katayama I. A novel application of topical rapamycin formulation, an inhibitor of mTOR, for patients with hypomelanotic macules in tuberous sclerosis complex. Arch Dermatol. 2012:148(1):138-9. doi:10.1001/archderm.148.1.138.

55. Wheless JW, Almoazen H. A novel topical rapamycin cream for the treatment of facial angiofibromas in tuberous sclerosis complex. J Child Neurol. 2013;28(7):933-6. doi:10.1177/0883073813488664.

56. Foster RS, Bint LJ, Halbert AR. Topical $0.1 \%$ rapamycin for angiofibromas in paediatric patients with tuberous sclerosis: a pilot study of four patients. Australas J Dermatol. 2012;53(1):52-6. doi:10.1111/j.1440-0960.2011.00837.x.

57. Krueger DA, Wilfong AA, Holland-Bouley K, Anderson AE, Agricola K, Tudor $C$ et al. Everolimus treatment of refractory epilepsy in tuberous sclerosis complex. Ann Neurol 2013. doi:10.1002/ana.23960.

58. Canpolat M, Per H, Gumus H, Yikilmaz A, Unal E, Patiroglu T et al. Rapamycin has a beneficial effect on controlling epilepsy in children with tuberous sclerosis complex: results of 7 children from a cohort of 86 . Childs Nerv Syst 2013. doi:10.1007/s00381-013-2185-6.

59. Tiberio D, Franz DN, Phillips JR. Regression of a cardiac rhabdomyoma in a patient receiving everolimus. Pediatrics. 2011;127(5):e1335-7. doi:10.1542/ peds.2010-2910.

60. Pressey JG, Wright JM, Geller JI, Joseph DB, Pressey CS, Kelly DR. Sirolimus therapy for fibromatosis and multifocal renal cell carcinoma in a child with tuberous sclerosis complex. Pediatr Blood Cancer. 2010;54(7):1035-7. doi:10.1002/pbc.22401.

61. Franz DN, Belousova E, Sparagana S, Bebin EM, Frost M, Kuperman R, et al. Efficacy and safety of everolimus for subependymal giant cell astrocytomas associated with tuberous sclerosis complex (EXIST-1): a multicentre, randomised, placebo-controlled phase 3 trial. Lancet. 2013;381(9861):125-32 doi:10.1016/S0140-6736(12)61134-9.

62. Bissler JJ, Kingswood JC, Radzikowska E, Zonnenberg BA, Frost M, Belousova

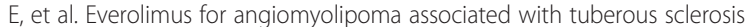
complex or sporadic lymphangioleiomyomatosis (EXIST-2): a multicentre, randomised, double-blind, placebo-controlled trial. Lancet. 2013;381(9869):817-24. doi:10.1016/S0140-6736(12)61767-X.

63. Koenig MK, Hebert AA, Roberson J, Samuels J, Slopis J, Woerner A, et al. Topical rapamycin therapy to alleviate the cutaneous manifestations of tuberous sclerosis complex: a double-blind, randomized, controlled trial to evaluate the safety and efficacy of topically applied rapamycin. Drugs R D. 2012;12(3):121-6. doi:10.2165/11634580-000000000-00000 